\title{
Chloromatous Tumours in African Children in Uganda*
}

\author{
J. N. P. DAVIES, $\dagger$ M.D. ; R. OWOR, $\ddagger$ M.B., CH.B.
}

Brit. med. F., 1965, 2, 405-407

Considerable attention has recently been paid to the neoplasms of children on the African continent because of the recent recognition of the great frequency, bizarre symptomatology, and unusual geographic distribution of the lymphoblastic lymphoma of childhood (Burkitt, 1963). Two theories have been put forward regarding this neoplasm. O'Conor and Davies (1960) suggested that it might be a biological equivalent of lymphatic leukaemia in children in other continents, a view which commended itself to Dalldorf (1962), because leukaemias and lymphomas together seemed to form much the same proportion of the total neoplasms of childhood in East Africa and the U.S.A. This has been disputed (Edington and Maclean, 1964). Alternatively it was suggested that from the epidemiology of of the disease it might be a virus-induced neoplasm spread by an insect vector (Burkitt and Davies, 1961). This latter suggestion led to search for a possible viral agent, and isolations have been reported by Dalldorf and Bergamini (1964) and by Bell et al. (1964), though the exact nature of these viruses and their relation to the lymphoblastic lymphoma are not clear and are under investigation. The two theories are not mutually exclusive, but they have led us to consider the behaviour of other tumours in African children to see if there were other anomalous conditions which might be of relevance to the situation. We are here reporting the unusual situation in Uganda with regard to chloromas.

\section{Chloromas}

Green coloration of organs, tissues, and fluids is not uncommon in cases of myeloid leukaemia, and non-pigmented tumorous masses of neoplastic cells, the "myeloblastomas" of Reardon and Moloney (1961), are well recognized. The true chloromas, the soft green-pigmented tumours, have attracted attention out of all proportion to their frequency, for they are barely mentioned in some books dealing with neoplasms of childhood (Ariel and Pack, 1960 ; Willis, 1962), and reviewers usually refer to them as rare or very rare (Atkinson, 1939). No figures seem to have been published by which their frequency, either vis-à-vis other neoplasms of children or of adults or vis-à-vis non-chloromatous myeloid leukaemias, can be judged. Perhaps because of their rarity nothing seems to have been written regarding their epidemiology or geographic pathology, though, considering the paucity of studies of leukaemia in Africa, it may be significant that the Bibliography on Cancer in Africa (1963) notes several case reports of chloromas. Their epidemiology would appear to be of interest, because the suspicion is held by many clinicians, and expressed by Hayhoe (1960), that they were more commonly seen in the past than in recent years despite the predominance now of leukaemia as a cause of death in childhood.

\section{Material}

During the period $1948-61$ one of us (J. N. P. D.) collected all cases of neoplasia in children under 15 years that were seen

\footnotetext{
* This work was supported by Grant DRG-830 from the Damon Runyan Memorial Fund for Cancer Research

† Department of Pathology, Albany Medical College, Albany, New York. $¥$ Department of Pathology, Makerere University College Medical School, Kampala, Uganda.
}

in the files of the Government Medical Laboratory in Kampala, which provided a biopsy service for the whole of Uganda. All cases in the years 1951-61 which were seen in the Kampala hospitals were included in the Kampala Cancer Survey whether histologically verified or not. It turned out that the proportion of chloromas to leukaemias was the same in the two series, so they have been combined. Material from 1961 to 1964 has been collected by one of us (R. O.) from the Pathology Department of the Medical School, which now provides a diagnostic service for the whole country. The proportion of chloromas to leukaemias and the frequency of leukaemias as a percentage of neoplasias in children do not appear to have altered in the period 1948-64.

As has been previously pointed out, leukaemias are not commonly diagnosed in African children (Davies, 1960), and in a total of 578 childhood neoplasms from Uganda (1948-60) there were only 25 cases of leukaemia. Despite recent interest in childhood neoplasms the frequency of leukaemia remains low (Dalldorf, 1962). In Nigeria Edington and Maclean (1964) recorded only 13 leukaemias in 298 childhood neoplasms.

In our present series of 32 cases of leukaemia in African children in Uganda there were eight cases of chloroma; there may have been more, as complete necropsies were carried out on only six children with leukaemia. Of the 32 leukaemias six were acute and unclassified, 13 were lymphatic leukaemia, five were non-chloromatous myeloid leukaemias, and eight were chloromas. The diagnosis of these chloromas was in all cases save one made at biopsy or necropsy because of the typical green colour of the tumour, and was confirmed in all cases by biopsy. The one clinical case not immediately recognized was that of a girl of 12 years who presented with what was thought to be osteomyelitis of the left tibia and of the right elbow region. On incision masses of green material, thought at first to be pigmented pus, were removed at each site; negative on culture, it was histologically chloromatous tissue. Details of this and the other cases are given in Table I. In six cases the tumours were in the orbits, causing proptosis, and in one the occipital bone was involved. Four were males and four females, and chloromas were relatively more frequent above the age of $6(6 / 16)$ than up to the age of $6(2 / 16)$ (see Histogram). The clinical presentations and the rapidly progressive course were similar to those cases seen elsewhere, as were the blood and bone-marrow changes where these were examined.

\begin{tabular}{|c|c|c|c|c|c|c|c|}
\hline $\begin{array}{l}\text { Case } \\
\text { No. }\end{array}$ & Age & Sex & $\begin{array}{c}\text { Site of } \\
\text { Tumour Mass }\end{array}$ & Biopsy & Necropsy & $\begin{array}{l}\text { Blood } \\
\text { Exam. }\end{array}$ & Fate \\
\hline $1 \mathrm{~J} 119 / 54$ & $3 \frac{1}{2}$ & F & Occipital bone & + & 0 & - & \\
\hline $\begin{array}{ll}2 & 585 / 58 \\
3 & 347 / 64 \\
4 & 152 / 58 \\
5 & \mathrm{J430/60} \\
6 & 437 / 58 \\
7 & \mathrm{~J} 1129 / 60 \\
8 & 162 / 64\end{array}$ & $\begin{array}{r}5 \\
8 \\
8 \\
9 \\
12 \\
12 \\
12\end{array}$ & $\begin{array}{c}M \\
M \\
\mathrm{~F} \\
\mathrm{~F} \\
\mathrm{~F} \\
\mathrm{M} \\
\mathrm{M}\end{array}$ & $\begin{array}{l}\text { Orbits } \\
\text { Orbit } \\
\text { Orbits } \\
\text { Orbit } \\
\text { L.tibia, R. elbow } \\
\text { Orbit } \\
\text { Orbit }\end{array}$ & $\begin{array}{l}\overline{+} \\
\pm \\
+ \\
+ \\
+ \\
+\end{array}$ & $\begin{array}{l}+ \\
0 \\
\pm \\
\pm \\
= \\
=\end{array}$ & $\begin{array}{l}+ \\
+ \\
\pm \\
+ \\
\pm \\
-\end{array}$ & $\begin{array}{l}\text { Died } \\
\text { Unknown } \\
\text { Died } \\
\text { Unknown } \\
\text { Died } \\
\text { Unknown } \\
\text { Unknown }\end{array}$ \\
\hline
\end{tabular}

In contradistinction to earlier views on the cell type in chloromas it has been generally agreed since the work of Brannan (1926) that they are all myelocytic in nature, and we have found nothing in these cases to controvert this view. So out of a total of 13 cases of myeloid leukaemia in African children in Uganda no fewer that eight were chloromas. Chloromas 
are thus neither very rare nor even uncommon in African children in Uganda, being in fact the commonest mode of presentation of myeloid leukaemia in children.

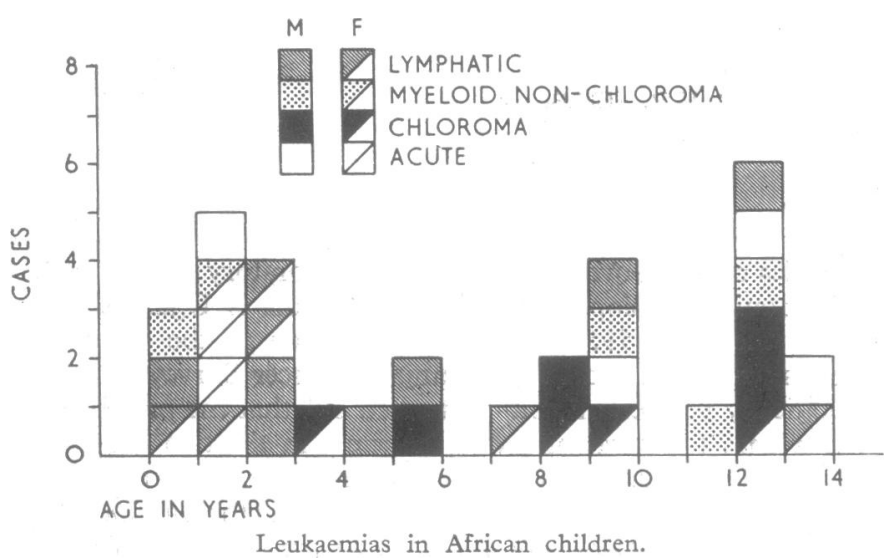

\section{Discussion}

As regards leukaemias and lymphomas in children in Uganda and in Africa, the striking feature is the reversed ratio of leukaemias and lymphomas as compared with other continents (O'Conor and Davies, 1960). All series of children's tumours published from Africa show this reversal (Table II). In tropical African series the major cause of the reversal is the lymphoblastic lymphoma, but even in Egypt, where this tumour has not been reported, El Gazayerli and Khalil (1961) recorded 14 leukaemias to 41 lymphomas, and of the 281 childhood lymphomas in the Kampala Survey at least 35 were not of the common lymphoblastic type, so that the ratio is still reversed even if lymphoblastic lymphomas are excluded. Now it is evident, at least in Uganda, that chloromas are remarkably frequent both in total frequency and in relation to leukaemias.

\begin{tabular}{|c|c|c|c|c|}
\hline & \multicolumn{2}{|c|}{ European } & \multicolumn{2}{|c|}{ African } \\
\hline & 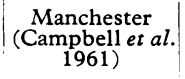 & $\begin{array}{c}\text { Norway } \\
\text { (Bjelke, 1962) }\end{array}$ & $\begin{array}{c}\text { Nigeria } \\
\text { (Edington and } \\
\text { Maclean, 1964) }\end{array}$ & Uganda \\
\hline $\begin{array}{lc}\text { Total children's } \\
\text { neoplasms }\end{array}$ & $\begin{array}{c}470(100 \%) \\
129(27 \cdot 4 \%) \\
41(0.7 \%(\%)\end{array}$ & $\begin{array}{r}640(100 \%) \\
221(34.8 \%) \\
61(9.5 \%)\end{array}$ & $\begin{array}{c}230(100 \%) \\
13(5.6 \%) \\
170(73.9 \%)\end{array}$ & $\begin{array}{r}578(100 \%) \\
25(4.3 \%) \\
281(48.6 \%)\end{array}$ \\
\hline
\end{tabular}

The first consideration is that these anomalies would be explicable were there gross underdiagnosis of leukaemia in children in Uganda and elsewhere in Africa. Reasons why this was unlikely have been given elsewhere (Davies, 1960), but as reference is here made to Ugandan and Nigerian experience it should be pointed out that in both countries the University Hospitals have active paediatric and haematological services, and the frequency of sickle-cell disease has enforced careful studies of the haematology of children in both centres, yet this has not increased the frequency of diagnosis of leukaemia in children, in the case of Uganda over a sixteen-year period with many changes in the diagnostic staff.

A measure of the possible degree of underdiagnosis could be estimated by calculating the number of cases of leukaemia required to bring the ratios of leukaemia:lymphoma and of chloroma: leukaemia into concordance with ratios prevailing elsewhere. Even crude calculations show that several hundred cases would be needed. But the actual incidence of cancer in children in one area of Uganda is known (Davies et al., 1962, 1965 ; Davies, 1964) and the rates are closely concordant to those of the U.S.A. and Norway. It is therefore clear that there is no room to fit in a large number of leukaemias postulated as missing without inflating the cancer incidence rates in children in Uganda to several times higher than those of Norway and the U.S.A. While not impossible this is so unlikely, considering the many other causes of death of children in Uganda, that it can be dismissed.

O'Conor and Davies (1960) and Dalldorf (1962) drew attention to the concordance of total lymphoma leukaemia figures in children's neoplasms in the U.S.A. and Africa in suggesting that the lymphoblastic lymphoma might be a biological equivalent of the ordinary lymphatic leukaemia. From the figures of Edington and Maclean (1964) it would appear that the incidence of lymphoblastic lymphoma in Nigeria is higher than that of lymphatic leukaemia in non-white children in the U.S.A., and Uganda experience would seem to support this. Stansfield (1961) found no evidence of leukaemic transformation of lymphoblastic lymphoma in Uganda, but Clift et al. (1963) showed that a leukaemic transformation could take place occasionally, usually as a terminal event, but that leukaemic transformation was an uncommon change. This situation in lymphoblastic lymphoma is that localized tumour deposits arise, remain localized, and usually kill the patient without leukaemic transformation.

The situation in chloromas is different; while an aleukaemic phase may persist for a short time, blood or marrow evidence of a leukaemic process is always present and almost all cases soon develop a frankly leukaemic picture. But, while the two situations are not exactly similar, it is interesting and perhaps of considerable significance that localized tumours in children in Uganda are common both in lymphoblastic lymphoma and in myeloid leukaemia. It raises the question of possible dual factors-one causative of a lympho-reticular and haemopoietic neoplastic transformation, and one which tends to keep such neoplastic processes localized rather than diffuse, a process more obvious in lymphoblastic lymphoma but evident also in myeloid leukaemia.

It is well recognised that the lymphoblastic lymphoma of children is not peculiar to Africa and that tumours with identical histology occur rarely in the U.S.A. (O'Conor and Davies, 1960 ; Gall, 1960 ; O’Conor, 1963), as they do on the highlands of South Africa (Gluckman, 1963). The causative factor is therefore not peculiar to Africa but only has a greater field of operation there. The situation is similar with regard to chloroma, and particular interest attaches to the widespread belief that chloromas occurred more frequently in the past than they have done in recent years. It will be interesting to see if the frequency of chloromas in Uganda diminishes with improvements in child health. If looked for, it might be possible to identify the factors which led to its decline.

\section{Summary}

In African children in Uganda there is a great and genuine deficiency of leukaemias and an excess of solid lympho-reticular tumours as compared with Europe and the U.S.A. The frequency of true chloromas is remarkably high; at least onequarter of all leukaemias are chloromatous. The implications of this are discussed, with particular reference to the common lymphoblastic lymphoma of African children.

\section{REFERENCES}

Ariel, I. M., and Pack, G. T. (1960). Cancer and Allied Diseases of Infancy and Childhood. Little, Brown, Boston.

Atkinson, F. R. B. (1939). Brit. F. Child. Dis., 36, 18. Bell, T. M., Massie, A., Ro

Bibliography on Cancer in Africa (1963). S. African Cancer Bulletin, Johannesburg.

Bielke, E. (1962). Cancer Registry of Norway. Personal communication. Brannan, D. (1926). Bull. Fohns Hopk. Hosp., 38, 189.

Burkitt, D. P. (1963). In Viruses, Nucleic Acids and Cancer. University of Texas and $M$. D. Anderson Hospital and Tumor Institute, Houston, Texas. Williams and Wilkins, Baltimore.

Campbell, A. C. P., Gaisford, W., Paterson, E., and Steward, J. K. (1961). Brit. med. F., 1, 448. 
Clift, R. A., Wright, D. H., and Clifford, P. (1963). Blood, 22, 243.

Dalldorf, G. (1962). F. Amer. med. Ass., 181, 1026.

- and Bergamini, F. (1964). Proc. nat. Acad. Sci. (Wash.), 51, 263.

Davies, J. N. P. (1960). Acta Un. int. Cancr., 16, 1618.

- (1964). New Engl. med. F., 270, 374.

- Wilson, B. A., and Knowelden, J. (1962). Lancet, 2, 328

$\overline{\text { Edington }}$ (1965). Unpublished.

Edington, G. M., and Maclean, C. M. U. (1964). Brit. med. 7., 1, 264

El Gazayerli, M., and Khalil, A. (1961). Alexandria med. F., $7,410$.
Gall, E. A. (1960). F. Pediat., 56, 584.

Gluckman, J. (1963). S. Afr. Cancer Bull., 7, 7.

Hayhoe, F. G. J. (1960). Leukaemia. Little, Brown, Boston.

O'Conor, G. T. (1963). Cancer Res., 23, 1514.

O'Conor, G. T. (1963). Cancer Res., 23, 1514. 52.

Reardon, G., and Moloney, W. C. (1961). Arch. intern. Med., 108, 864. Stansfield, D. (1961). Brit. F. Cancer, 15, 41 .

Willis, R. A. (1962). The Pathology of the Tumours of Children. Oliver and Boyd, Edinburgh.

\section{Medical Memoranda}

\section{Complication Following Insertion of Intrauterine Contraceptive Device}

Brit. med. F., 1965, 2, 407-408

Interest has recently been revived in the use of the intrauterine contraceptive device as a contraceptive measure, especially in the developing countries. Reports show that a failure rate of about $5 \%$ may be expected and that major complications have not been reported (Proceedings of Conference on Intrauterine Contraceptive Devices, 1963). This report describes perforation of the uterus and strangulation of the gut by an intrauterine contraceptive device.

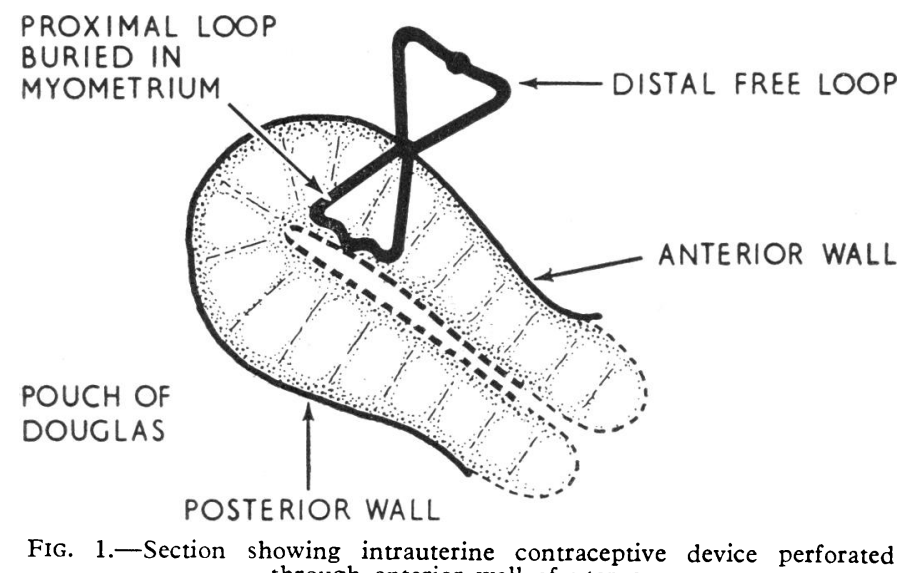

FIG. 1.-Section showing intrauterine contraceptive device perforated through anterior wall of uterus.

\section{CASE Report}

A 29-year-old Chinese woman, who had had seven children and no abortions, was admitted on 28 December 1964 to the General Hospital, Kuala Lumpur. She gave a history of severe colicky epigastric pain of three hours' duration, during which she had vomited three times. She had opened her bowels once the previous day. Her last child had been delivered on 9 June 1964. Since this birth she had been breast-feeding and was amenorrhoeic. She had been seen at the post-natal clinic six weeks after delivery, and a Birnberg Bow Plastic intrauterine device (size 4) was inserted on 22 July 1964. There was no question of the uterine wall being damaged during the insertion of the device. It had been inserted by an experienced doctor, and a pelvic examination had been carried out after the insertion. The patient was followed up at regular intervals, and at each visit a detailed history was taken and a pelvic examination carried out. No abnormality had been complained of or detected.

Examination on admission showed that she was in a state of shock with signs of intra-abdominal bleeding. The abdomen was tender in the hypogastrium and shifting dullness was present. Vaginal examination showed a soft cervix with a closed os. There was fresh bleeding through the os, the cervix was tender on movement, and the uterus was anteverted and about six weeks by size. A vague mass occupied the pouch of Douglas. A provisional diagnosis of ruptured ectopic pregnancy was made and laparotomy performed.

At laparotomy $800 \mathrm{ml}$. of blood which had come from the ruptured site was found in the peritoneal cavity. The distal loop of the intrauterine device was sticking through the anterior wall of the uterus, the proximal loop being firmly embedded in the myometrium (Fig. 1). A loop of the ileum about $2 \mathrm{ft} .(183 \mathrm{~cm}$.) in length had herniated through the free loop of the intrauterine device and had strangulated (Fig. 2). The strangulated gut was very firmly constricted at the point of entry. The uterus was about six weeks by size, and mobile. There were multiple fine adhesions on the posterior wall of the uterus.

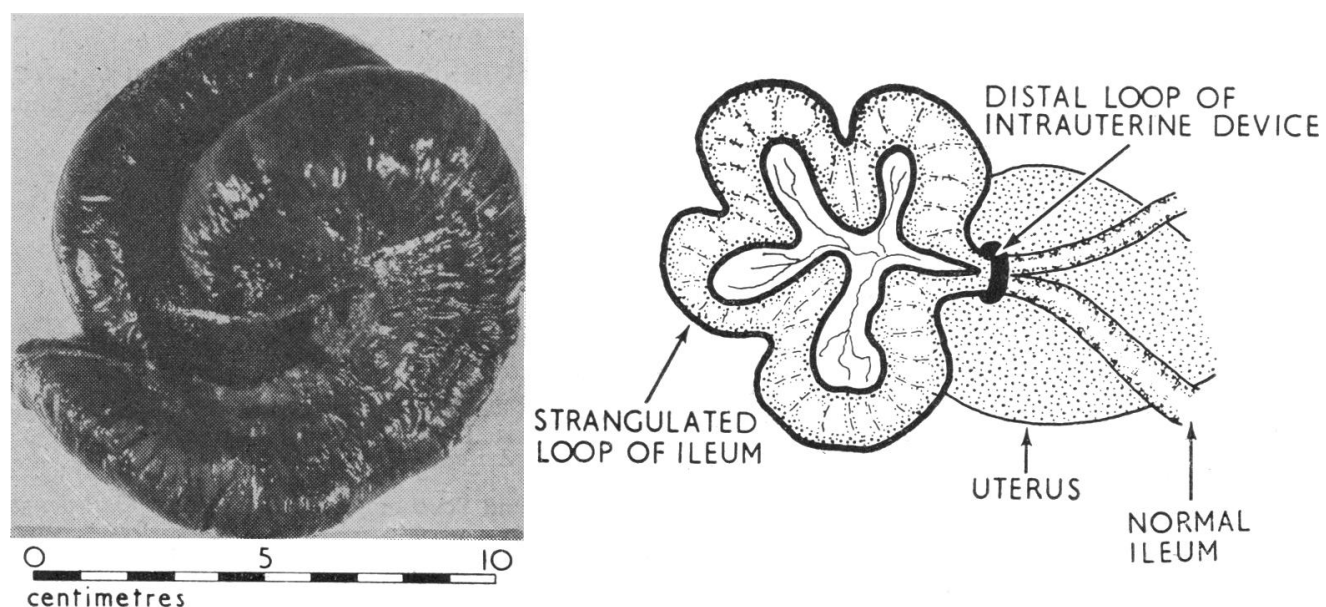

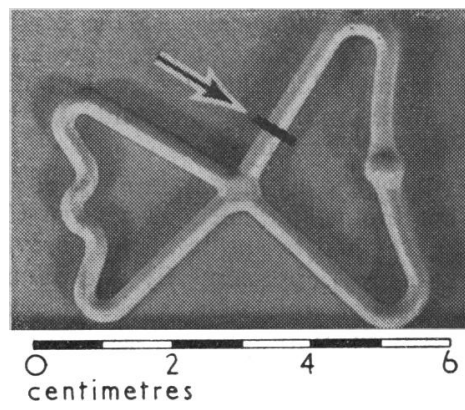

FIG. 3.-Intrauterine contraceptive device Birnberg Bow (size 4), showing site at which it was cut to release strangulated gut.

FIG. 2.-Photograph and drawing of strangulated loop of ileum. 